\title{
Trends in Agriculturally-Relevant Rainfall Characteristics for Small-Scale Agriculture in Northern Ghana
}

\author{
Genesis Tambang Yengoh \\ Department of Earth \& Ecosystem Sciences, Lund University \\ Sölvegatan 12, SE-223 62 Lund, Sweden \\ Tel: 46-46-222-222-8416_E-mail: yengoh.genesis@lucsus.lu.se \\ Frederick Ato Armah \\ Department of Environmental Science, University of Cape Coast, Ghana \\ E-mail: atoarmah@yahoo.com \\ Edward Ebo Onumah \\ Department of Agricultural Economics and Agribusiness \\ University of Ghana, Legon - Accra, Ghana \\ E-mail: eonumah@gwdg.de \\ Justice O. Odoi \\ Ghana Nature Today, A 25 Standard Estates \\ Sakumono, P.O. Box OS 1455, Osu, Accra, Ghana \\ E-mail: justice20gh@gmail.com
}

\begin{abstract}
This study set out to investigate the trends of agriculturally-relevant rainfall characteristics among small-scale farmers in the rainfall-sensitive dry savanna agro-ecological zone of northern Ghana. Interviews are used to identify characteristics of rainfall which are deemed by the farmers as important in their food production. Time series daily rainfall data from 1960-2007 is then used to identify trends in these variables which include the amount and temporal distribution of rainfall, occurrence of extreme daily rainfall events, the onset of rains, risk of dry spells and coefficient of variability of rains. The risk of dry spells for varying number of days following the planting period is computed using first-order Markov chain modeling. We find that there is a significant increase in mean rainfall per rain day and the coefficient of variation or summer rainfall amounts. No significant change in the onset of rains, the annual rainfall amount or maximum rainfall days are established. However, a significant decrease in the number of rain days and the probability of dry spells of up to seven and eleven days in the first four weeks of the planting season is revealed. There is need for development of an agricultural policy framework designed to understand the growing risks associated with agricultural production among small-scale farmers, and to improve management practices to accommodate and adapt to the new challenges of varying rainfall.
\end{abstract}

Keywords: Rainfall variability, Farming, Northern Ghana, Statistics, Risk of dry spells, Markov chain modeling

\section{Introduction}

Climatic factors play an important role in determining the production of food crops in the semi-arid regions of Africa. This is a region characterized by a low and highly variable distribution of rainfall spatially and over time, which constitutes a limiting potential for crop yields (Tesfaye et al. 2004; Graef et al., 2001). The amount of rainfall and its distribution over the year (especially during the farming season) greatly affects the productivity of agriculture in these regions. It determines the types of crops to be grown, the presence or absence of support activities like irrigation and crop yields, as well as influences agricultural calendar. The start of rains marks the start of the main farming season in northern Ghana as well as most parts of the Guinea savanna and the Sudano-sahelian region of Africa. This is usually considered to be the planting period for some of the main 
staple crops of the region, such as maize, beans and potatoes (Stumpf, 1998). After planting, small-scale farmers usually engage in other small income generating activities on the side.

Rainfall in this region is lower than in the equatorial tropical belt and is variable both spatially and seasonally. This low and variable nature of rainfall imposes a delicate balance between the onset, duration and amount of rain and the timing of agricultural activities. Climatic manifestations over the last decade have made it difficult to maintain this fragile balance. During the last decade, climate-related crop failures in the Sudano-Sahelian region of Africa have attracted regional and global attention. Among many manifestations of climatic instability and change have been floods that devastated large areas of near-ready grain fields, several episodes of late rains during planting seasons, and persistent droughts in large portions of the region. Studies show that elements of climate change (increasing temperatures and declining precipitation) are likely to reduce yields of corn, rice, wheat and other main food crops in this region (Lobell et al., 2007). As climate change takes hold, it is necessary to adapt agriculture to the changing patterns of manifestation of climatic elements (especially rainfall, which is the main determinant of agricultural production in this region). A proper understanding of the characteristics of variation of rainfall is necessary in guiding agricultural planning. This study therefore seeks to identify the trends in rainfall-related climatic indices that are agriculturally relevant to small-scale farmers of the northern region of Ghana.

Three reasons underlie the choice of northern Ghana for study. Firstly, of all, this zone is very sensitive to variability of climate elements. For instance, the early part of the 2007 farming season (mid-May to June) in northern Ghana (like most of the Guinea savanna and Sudano-sahelian belt of Africa) was affected by an exceptionally long dry spell following early rains in April and early May. When the rains resumed, many farmers replanted only for the crops to be washed away by extensive floods. Many of these farmers are unlikely to recover without external assistance (FAO, 2007). Secondly, a snapshot of northern Ghanaian livelihoods shows that many households are heavily dependent on agriculture and see limited opportunities outside of the agricultural sector. However, they are unable to emerge out of poverty due to low asset levels (including capital and land) that reduce the possibilities for saving and investment in a highly risky environment where shocks regularly force them to liquidate their assets or divert them away from agriculture simply in order to survive (Sachs, 2008). Those households relying heavily on agriculture for their livelihoods are vulnerable in particular to climatic shocks, such as bushfires, droughts and floods, sometimes with more than one of these calamities occuring in one year. Other risks arise from market volatility, the rising price of agricultural inputs, and human risks such as susceptibility to disease and malnutrition (NDPC, 2004). Where they are able, households take measures to reduce their exposure to risk (for example, by diversifying their income sources through migration and remittances, planting improved seed varieties or multi-cropping). Coping strategies clearly depend on the shock in question, but include: sale of assets including livestock, reduction in food intake, engaging in petty trade, migration, children dropping out of school to enter the informal labour market, and self-medication or use of unorthodox sources of medicine and medical practices. It also includes reliance on other family members, community based organizations (CBOs) or other non-governmental organizations (NGOs) for assistance (FAO, 2007). Thirdly, after a quarter of a century of Structural Adjustment Programmes (SAPs), all regions of Ghana appear to have witnessed significant reductions in poverty level, except Northern Ghana. Poverty levels in northern Ghana linger around 52-88\% (FAO, 2007). Poverty appears to be concentrated amongst food crop farmers who are particularly dependent on rain-fed agriculture. Poverty in Ghana is considered to be increasingly intense in the northern part, remote from Accra and international markets (although well placed for cross-border trade with Sahelian countries), and related to households for whom production of low-value food crops is a major livelihood activity (FAO, 2007). Climate-related manifestations have also contributed to the socio-economic situation of this region. For example, since 1980, six major floods have affected many parts of this region - in 1985, 1988, 1993, 1998, 1999 and 2007.

This study uses three main methods to highlight the trends of agriculturally-relevant rainfall characteristics for small-scale farmers in northern Ghana. Interviews are used to identify agriculturally-relevant rainfall characteristics for small-scale farmers in northern Ghana. Statistics are then used to reveal daily, monthly, seasonal and annual trends as well as the coefficient of variation (CV) of rainfall. We use Markov chain modeling to estimate probabilities of dry spells for the first months of the onset of the rainy season.

\section{Study Area}

Tamale $\left(9.40^{\circ} \mathrm{N}\right.$ and $\left.0.83^{0} \mathrm{~W}\right)$ is found in the Guinea savanna agro-ecological zone in the Northern Region of Ghana (Figure 1). Tamale is surrounded by villages with high population densities and lies 183 metres above sea level on a plain $(35 \mathrm{~km})$ east of the White Volta River. The metropolis serves as the administrative, financial, commercial, and transportation centre for Northern Ghana. Tamale Metropolis is documented as the fastest 
growing city in West Africa with a population of 40,443 in 1960, and about 3,000,000 in 2009 (Seidu, 2009). As a metropolitan district some $39 \mathrm{~km}$ across, Tamale comprises at least 160 villages, some that are concealed in the centre of town, but many others that are still exclusively rural. In town there is hardly any remaining arable land, so villagers must travel to find farmland, often at considerable distances (MacGaffey, 2009). It covers a land area of about $750 \mathrm{~km}^{2}$ (Seidu, 2009). There is no major river passing through Tamale and the ground water table is low.

$<$ Figure 1>

Tamale is also an important agricultural region for the country, producing some of the most important food crops consumed in the country such as maize, rice sorghum, millet, yam, cassava and groundnuts. This area is found in the Inter-tropical Convergence Zone (ITCZ) and has a tropical grassland climate with a distinct wet season (approximately April-September) and dry season (October-March). Rainfall is therefore strongly influenced by and dependent on the trade winds converging on the ever-displacing Inter-tropical Convergence Front (Sultan et al. 2005). In the floods of September and October 2007 and 2008, this region was one of the most severely affected areas. Being an important source of food crops for the country as a whole, the crisis of food shortages and price increases was further intensified for Ghana.

\section{Methods}

\subsection{Data and sampling technique}

In-depth interviews were conducted in seven communities with a total of 46 small-scale farmers in the Tamale area. The aim of these interviews was to establish what constitutes agriculturally-relevant rainfall characteristics for small-scale farmers in the region. Farmers were randomly selected with the guide of agricultural extension officers in the communities concerned. The sample group interviewed population aged between twenty-five and sixty years of age and had all been living and practicing agriculture in their communities for more than three years. The core question posed to farmers was aimed at knowing which characteristics of rainfall were relevant for their practice of agriculture. Discussions that followed were aimed at knowing how farmers perceived trends of the factors they identified as relevant.

Daily rainfall data from Yendi, Wa and Tamale covering the period 1960-2007 was obtained from the Ghana Meteorological Service in Accra. After preliminary assessments, records for Yendi and Wa were eliminated from further processing because they had large numbers of missing daily data and were incomplete for many months between 1980 and 1985 as well as between 1992 and 1998. After screening for consistency and completeness, $0.06 \%$ points of missing daily data for Tamale were replaced by the average of the nearest future and past observations. There were no points of more than one consecutive day of missing entries in the dataset.

\subsection{Data analysis}

Daily rainfall amounts are summed into annual, seasonal and monthly totals. These totals are then plotted against their long-term means and fitted with trend lines to observe the overall tendency of each dataset relative to its average long-term trend. The $\mathrm{CV}$ is a unitless normalized measure of dispersion of a probability distribution. It expresses the standard deviation as a fraction of the mean and is useful when interest is in the size of variation relative to the size of the observation. In comparing different years of rainfall with different means, the coefficient of variation is therefore a more useful basis of comparison than the standard deviation. It is expressed as the ratio of the standard deviation $\sigma$ to the mean $\mu$ (Equation 1). Hence,

$$
C . V=\frac{\sigma}{\mu}
$$

The coefficient of variation is used to compare the long-term variation of wet season (approximately April-September) rainfall to that of individual years. This gives an estimate of the degree to which rainfall in the wet season months which are important for agriculture is either stable or changing. Such a change is important for agriculture in Tamale and the rest of northern Ghana because the majority of the agricultural activities and the production of most food crops take place during this period. The onset of the rainy season is used to investigate changes in the start of the food crop planting period in Tamale. For purposes of this study, the onset of rains is defined as the first occasion from the 1st of April that registers $20 \mathrm{~mm}$ of rain or more over a 6-day period, and does not have a dry spell of more than 7 days in the subsequent 30 days.

Regressions are used to estimate temporal trends in rainfall records. The suitability of data for regression analysis, approximation techniques and the interpretation of results are discussed (Llyod, 2009; Cheng et al, 2004; Stern et al. 1984). They have been used in a number of case studies (Kumar et al. 2010; Lehmann et al. 
2005). We perform linear regressions on time series data (annual amount of rain, number of days of rainfall, mean rainfall per rain day and the annual daily maximum rainfall events). The t-test is used to evaluate the presence of trends.

When processes are seen as a succession of stages in sequence, then each stage may be described by a Markov process (Sansom, 1998). Markov models have been used as tools for fitting sequences of daily rainfall occurrence for Tel Aviv data (Gabriel et al., 1962) as well as for estimating frequencies and lengths of spells (Barron et al., 2003; Sharma, 1996; Stern et al., 1984). The Markov property specifies that the probability of a state depends only on the probability of the previous state. Regarding rainfall which is assumed to be a stochastic event, the probability of rain falling in any given day is dependent on the probability of the previous day being dry - the probability of rain-given-dry $\mathrm{P}(\mathrm{rd})$, or the previous day being wet - the probability of rain-given-rain $\mathrm{P}(\mathrm{rr})$ (Equation 3 and Equation 4). This is described as a first order Markov process because it goes back one time step (Barron et al. 2003; Stern et al, 1998). It is therefore possible to build more "memory" into a state by using a higher order Markov model. For a dataset, the sequence of wet days $\left(x_{j}=0\right)$ and dry days $\left(x_{j}=1\right)$ is described as (Barron et al. 2003):

$$
\begin{aligned}
& Q_{t}=\left\{x_{1}, x_{2}, \ldots, x_{j-1}, x_{j}\right\} \quad \text { for } \\
& Q_{t}=\{1,2,3, \ldots,-1,0
\end{aligned}
$$

Where:

$\boldsymbol{x}_{\boldsymbol{j}}=$ a day in sequence

$\boldsymbol{Q}_{\boldsymbol{i}}=$ each year in the dataset

$\boldsymbol{i}=$ the number of years of observation

$\boldsymbol{j}=$ the day number of the year from 1 (1st January) to 366 (31st December)

The probability for a day being rainy following a dry day (that is the probability of rain-given-dry $\mathrm{P}(\mathrm{rd})$ ) can be computed as:

$$
\begin{gathered}
P(r d)=\operatorname{prab}\left(x_{j}=1, x_{j-1}=0\right) \\
=\frac{\sum_{q-1}^{q-1}\left(x_{j}=1, x_{j-1}=0\right)}{\sum_{0=1}^{q-1}\left(x_{j-1}=0\right)}
\end{gathered}
$$

In the same way, the probability of a rainy day following a rainy day (in other words the probability of rain-given-rain $\mathrm{P}(\mathrm{rr})$ ) can be given as:

$$
\begin{gathered}
F(r)=\operatorname{prab}\left(x_{\gamma}=1 x_{/-1}=1\right) \\
=\frac{\sum_{-1}^{q-t}\left(x_{\gamma}=1, x_{/-1}=1\right)}{\sum_{-1}^{q-t}\left(x_{\gamma-1}=1\right)}
\end{gathered}
$$

A function is fitted to the estimated probabilities using Fourier analysis (Barron et al. 2003). A number of harmonics is tested until a best fit is achieved by $F$-test. The determined function(s) of probability of rainfall on any given day is then used to establish probabilities of the occurrence of dry spell for different durations (in this case 7, 11, 15 and 21 days for the months of April and May). A Markov chain model was curve fitted to the overall chance of rain with an initial complexity of four harmonics. The fitted model was used to estimate the risk of dry spell lengths of 7 to 21 days for the months of April and May, which are crucial months for the initial life of most food crops planted in the rainy season in northern Ghana. A similar process was used to estimate rainfall probability per rain day and the mean rainfall amount per rain day. The assumptions and restrictions of fitting first and second-order Markov models are explained in Stern and Coe, (1984). INSTAT ${ }^{\mathrm{TM}}$ software developed by the Statistical Services Center, University of Reading, United Kingdom is used for the Markov modeling process. 


\section{Results and Discussion}

\subsection{Results of interviews - relevant rainfall characteristics for Northern Ghana}

The most important agriculturally-relevant rainfall characteristics identified by farmers were: the amount and distribution of summer rainfall, reliability of rainfall after planting, rainfall variability and the occurrence of excessively high daily rainfall events that may trigger floods.

- Amount and distribution of rainfall over the summer period (April-Sptember).

The summer period is the only farming period in this region for most small-scale farmers. This is because most small-scale farmers (who make up the bulk of the farming population) cannot afford investments in irrigation and therefore practice mainly rain-fed farming.

- $\quad$ Reliability of rainfall during the first four weeks after planting (risk and length of dry spells).

The first few weeks after planting are important for most plant cultivated in this region. They are still young, fragile and can be damaged by many consecutive days of no rain (long dry spells).

\section{- Variability of rains}

The ideal rainfall in Northern Ghana is one in which rainfall builds up gradually to a peak in August, and then declines more rapidly, but steadily and gives way to the dry season in the end of September. When heavy rains are interspersed with many consecutive days of very low or no rainfall, crop failures may occur. These may be due either to the proliferation of pests or limited water at times when plants are most in need.

- Occurrence of excessively high daily rainfall that may trigger floods and erosion of the topsoil.

Over the last fifteen years, 6 major floods have caused different scales of crop damage in Northern Ghana. While most flood events are triggered by several days of heavy rains, farmers have tended to view each exceptionally heavy event with apprehension.

\subsection{Results of data analysis and implications for agriculture}

\subsubsection{No significant trend of change in annual amount of rain}

Summer is defined here as the period from the 1st April to the 31 st September. This is the period when all of the rain-fed agricultural activities take place in northern Ghana. Besides other rainfall characteristics, the total amount of rain during this period is important in determining the types of crops that are cultivated here. This is because the amount and distribution of rainfall in turn determines the availability of water for crop production (Tesfaye et al, 2004). Without sufficient rainfall during the rainy season, cassava and yams, the most important root crops in Ghana (Stumpf, 1998) may not be cultivated in this region. The equation of the straight line relating annual rainfall and time (in years) is estimated as: annual rainfall $=(5287.2107)+(-2.1114)$ time, using the 48 observations in this dataset. The slope, the estimated change in annual rainfall per unit change in time, is -2.1114 with a standard error of 2.0327 . The value of $\mathrm{R}^{2}$, the proportion of the variation in annual rainfall that can be accounted for by variation in time, is 0.0229 (Figure 2). A significance test that the slope is zero (there is no change in annual rainfall over time) resulted in a t-value of -1.0387 . The significance level of this t-test is 0.3044 , hence there is no statistically significant change in annual rainfall within the study period.

$<$ Figure 2>

An improvement of the rainfall situation after the trend of declining rainfall that marked the 1960s-1980s has been observed in the Sudan-Sahel region of Africa (Boko, 2007; Nicholson, 2005). This observation is corroborated with evidence of increased photosynthetic activity in the region (Seaquist et al. 2008; Olsson et al.2005). The Tamale dataset from the Guinea savanna region (not the Sudano-sahelian region from which most of the data used to establish this recovery has been taken) points to a stabilization of annual precipitation around the long-term mean of the study period. This observation fits well with observed trend of summer rainfall for the Sahel and ensemble mean of ten simulations with the GFDL CM2.0 climate model forced with sea surface temperatures (Houghton, 2009. pp.107). Prospects of recovery from a long and perilous cycle of drought and environmental decline offer optimistic expectations for development of agriculture and the social and economic life of residents in the region. Narratives of land and environmental degradation may be replaced by trajectories of sustainable agriculture and development (Olsson et al. 2008). While the total amount of summer rainfall shows no significant trend, other characteristics of summer rainfall show significant trends of change during the study period. These are the number of rain days and the mean rainfall per rain day from 1960-2007. 


\subsubsection{Decrease in the number of days of rainfall and increase in mean rainfall per rain day}

The number of days of rain is a marker that can be used to verify the distribution of rainfall. During the growing season of crops, farmers would ideally want a balance between the distribution of rain days and moderation in rainfall amounts per rain day throughout the season. From interviews, a good distribution of rain days implies the absence of long periods of dry spells and moderate amounts of rainfall implies rain input that does not have the potential of inducing floods or large-scale erosion. The number of days of rainfall shows a significant decrease within the study period. The equation of the straight line relating number of rain days and time is estimated as: number of rain days $=(915.4185)+(-0.4184)$ time. The slope, the estimated change in number of rain days per unit change in time, is -0.4184 with a standard error of 0.0993 . The value of $\mathrm{R}^{2}$ is 0.2786 (Figure 3 ). The correlation between number of rain days and time is -0.5279 . A significance test that the slope is zero (there is no trend) resulted in a t-value of -4.2153 . The significance level of this t-test is 0.0001 . Since $0.0001<0.0500$, the hypothesis that the slope is zero is rejected and conclude that the fall in the number of rain days is significant at $95 \%$ confidence level.

$<$ Figure $3>$

If the total amount of summer rain shows no significant decrease $\left(\mathrm{R}^{2}=0.0198\right)$ and the number of days of rainfall show a significant decrease $\left(R^{2}=0.0872\right)$, it is plausible to hypothesize an increase in mean rainfall per rain day to make up for the fewer days of rainfall. Mean rainfall per rain day of each year is the quotient of annual rainfall on number of rain days for that year. The long-term mean of daily rainfall per rain day since 1960 is $13 \mathrm{~mm}$. The value of $\mathrm{R}^{2}$ is 0.0872 (Figure 4). A significance test that the slope is zero resulted in a t-value of 2.0963. The significance level of this t-test is 0.0416 . Since $0.0416<0.0500$, the hypothesis that the slope is zero (there is no trend) is rejected. There is therefore a significant change in mean rainfall per rain day within the period 1960-2007.

$<$ Figure $4>$

The annual daily maximum rainfall events refer to the day in each year with the highest input of rainfall. The time series trend for these maximum daily rainfall events do not show any significant increasing or decreasing trend. Farmers tend to associate high intensity rainfall events with the occurrence of floods. However, not all of these daily rainfall maxima can be associated with incidences of floods. Since 1980, northern Ghana has registered six episodes of floods, two of them major and making international headlines. Most of the floods occur when high intensity rainfall, which may not necessarily be the maximum for the year, persists for several consecutive days. The value of $\mathrm{R}^{2}$ is 0.0174 (Figure 5). A significance test that the slope is zero resulted in a $\mathrm{t}$-value of 0.9027 . The significance level of this t-test is 0.3714 . Since $0.3714>0.0500$, the hypothesis that the slope is zero (there is no trend), is not rejected. There is therefore no statistically significant change in maximum daily rainfall for each year within the 48 year period of study.

$<$ Figure 5 $>$

A fall in the number of rain days associated with an increase in the mean input of rainfall per rain day signifies an increase in the intensity of rainfall. This increase in rainfall intensity (implying increase in mean rainfall per rain day) also corresponds well with projections of future climate change for the region (Kharin et al., 2005; Meehl et al., 2005; Boko et al., 2007). Previous studies have forecasted these increases in the tropical regions and attributed it to both dynamic and thermodynamic processes associated with global warming (Emori et al., 2005). Higher rainfall intensities could have a number of negative effects on agriculture both in the short and long-term. It increases the rate of erosion and loss of particulate nutrients from arable soils, thereby reducing soil fertility and productivity (Fraser et al. 1999). An increase in the intensity of rainfall may also harbor potentially serious risks of an increased flood frequency and severity for most regions of the world (Gordon et al., 1992; Fowler et al., 1995). While high daily rainfall inputs may be potentially destructive to agriculture in sensitive areas like Tamale, the destruction caused by rains may sometimes arise from the accumulation of several days of rain that fall slightly below the maximum rainfall events for that year. This was the situation in the summer of 2007 when which exceptionally extensive flooding destroyed fields, homes and granaries and led to the loss of large numbers of livestock in northern Ghana and many areas in the Guinea savanna and Sudano-sahelian agro-ecological zones of Africa (Armah et al. 2010; Karley, 2009). This compounded the problem of food shortages and led to unprecedented food price increases. These events were a result of several days of consecutive rainfall below the annual daily maximum rather than a single day of exceptionally high rainfall input. 


\subsubsection{No significant trend in the onset of rains}

The onset of the rainy season - defined as any day after April 1st in which rainfall totaled over six days is equal to or greater than $20 \mathrm{~mm}$ and in which after this period, no spell exceeding seven days is witnessed for the next 30 days. The slope, the estimated change in difference from mean start of rains per unit change in time, is 0.1449 with a standard error of 0.2335 . The value of $\mathrm{R}^{2}$ is 0.0083 (Figure 6). A significance test that the slope is zero (there is no trend) resulted in a $\mathrm{t}$-value of 0.6206 . The significance level of this t-test is 0.5379 . Since $0.5379>$ 0.0500 , the hypothesis that the slope is zero, is not rejected. We therefore conclude that there is no significant change in the onset of the rainy season.

$<$ Figure 6 $>$

The onset of rains season is a very important event in the lives of small-scale farmers in the Sudano-Sahel region of Africa. This onset marks the beginning of three main activities - planting, weeding and harvesting (Mortimore et al. 1999) - which determine the socio-economic life and survival of the farming household. The importance of farming in the lives of these households also means that other activities are based on the accomplishment of these three tasks (West et al, 2008). Planting, which depends and is influenced directly by the onset of the rainy season, is the first of these tasks and that on which the other two activities are based. Significant shifts in the onset of rains will therefore affect both agriculture and many other non-agricultural activities of small-scale farmers. Studies have reported how variability of the onset and cessation of the rainy season in tropical regions complicates the process of determining when the rainy season (and hence the planting season) begins (Mugalavai et al.2008; Oladipo et al. 1993; Camberlain et al. 2003). Even though farmers contend that the onset of rains is becoming more uncertain with a tendency towards delayed onset, the data shows no statistically significant trend indicating a late start of the rainy season

\subsubsection{More variable summer rainfall}

Opinions and allusions to a mean or equilibrium state rainfall for the Sahel and its adjoining regions have been contested. It is argued that the normal state of the Sahelian rainfall is rather a constant variation over space and time (Humle, 2001). Through interviews, we observe that farmers are not very interested in the year-to-year variation of rainfall but rather the intra-seasonal variation during each farming season. This makes an examination of the variation within each season even more interesting, especially considering the trend of this intra-seasonal variation throughout the study period. The value of $\mathrm{R}^{2}$ is 0.1578 (Figure 7 ). The correlation between coefficient of variation and time is 0.3973 . A significance test that the slope is zero resulted in a $t$-value of 2.9362. The significance level of this t-test is 0.0052 . Since $0.0052<0.0500$, the hypothesis that the slope is zero (there is no trend) is rejected. With $\mathrm{R}^{2}$ of 0.3973 , we conclude that the trend of increase in the coefficient of variation is significant. The long-term mean coefficient of variation is computed to be 2.3 .

\section{$<$ Figure $7>$}

For farmers in the northern region of Ghana, the total amount of rainfall during the rainy season is deemed to be generally sufficient for their crop requirements. They are however more concerned about the ever-present possibility of extremes in the availability or non-availability of the rain water they require for cropping. Dry spells are an important feature of agriculture in the dry lands of sub-Saharan Africa. Long dry spells at sensitive times of plant development (germination, flowering, seeding) could spell disaster for agriculturalists (Barron et al, 2003; Sivakumar, 1992). This adds to the vulnerability of small-scale farming systems in this region and constitutes one element in the mosaic of climate related challenges that agricultural production has to deal with (Enfors et al., 2007). Like reduced rainfall, long and frequent dry spells can have significant effects on the growth and yields of some seasonal crops such as maize, beans and potatoes. Reduced yield may lead to a fall in agricultural income and access to food for many in northern Ghana and other parts of the semi-arid regions of tropical Africa. Reduced yields may also trigger the co-opting of more land into agricultural production at the expense of conservation thereby leading to land degradation, which is an environmental problem (West et al. 2008). During prolonged drought periods, people tend to ensure food production at the expense of cash crops (Sivakumar, 1992). This rational survival strategy is all the more necessary for small-scale farmers with limited incomes, such as the majority in northern Ghana. The outcome could be a modification of the agro-ecological landscape.

\subsubsection{Probabilities of dry spells}

A first-order Markov model gives two rainfall probabilities for each day of the year: the probability that a day will be rainy or the previous days were rainy (rain-given-rain), and the probability that a day will be rainy if the 
previous day was dry (rain-given-dry), (Figure 8). The latter is greater than the former at the beginning and towards the end of the rainy season when drier conditions tend to prevail. Generally, the chance of rain grows from $0 \%$ in December and January to about $10 \%$ in April. It reaches a secondary peak of about $39 \%$ in June and the main peak of about $58 \%$ at the middle of September. After this time, the probability of rain falls sharply as the region enters the dry season.

$<$ Figure $8>$

The probability of dry spells of at least seven days is as high as 98 percent in the beginning of April and declines gradually to the beginning of May (Figure 9). By the end of May, there is still a 60 percent chance of a dry spell of seven days. At the beginning of April, there is a 75 percent probability of dry spells of 11 days. By the end of April, the chance of a 11 day dry spell is 45 percent and by the end of May, the probability is less than 20 percent. A 15-day dry spell is about 50 percent likely at the beginning of the planting season (the 1st of April). By the end of May, it is less than 20 percent likely. The risk of suffering losses when crops that are sensitive to dry spells of up to 10 days are planted in April $1^{\text {st }}$ is therefore more than 75 percent (Figure 9). This risk associted with the uncertainty of the start of the rainy season may partly explain the high degree of caution in deciding when to plant among farmers in northern Ghana.

$<$ Figure 9>

For farmers in the northern region of Ghana, the total amount of rainfall during the rainy season is deemed to be generally sufficient for their crop requirements. They are, however, more concerned about the ever-present possibility of extremes in the availability or non-availability of the rain water they require for cropping. Dry spells are an important feature of agriculture in the dry lands of sub-Saharan Africa. Long dry spells at sensitive times of plant development (germination, flowering, seeding) could spell disaster for agriculturalists (Barron et al, 2003; Sivakumar, 1992). This adds to the vulnerability of small-scale farming systems in this region and constitutes one element in the mosaic of climate related challenges that agricultural production has to deal with (Enfors et al., 2007). Like reduced rainfall, long and frequent dry spells can have significant effects on the growth and yields of some seasonal crops like maize, beans and potatoes. Reduced yield may lead to a fall in agricultural income and access to food for many in northern Ghana and other parts of the semi-arid regions of tropical Africa. Reduced yields may also trigger the co-opting of more land into agricultural production at the expense of conservation thereby leading to land degradation which is an environmental problem (West et al. 2008).

\section{Contributions of human activities on the rainfall situation in northern Ghana}

The occurrence of rainfall depends on geographic location, sea and land surface temperatures, proximity to water bodies, topography, winds, vegetation cover, and others (Meher-Homji, 1991). The role of vegetation cover as a factor of rainfall causation and the effects of anthropogenic activities like deforestation in modifying rainfall has been investigated and reported (Pielke, 2007; Webb, 2005; Meher-Homji, 1991). Deforestation affects rainfall through changing rates of physical evaporation, transpiration, surface albedo, and aerodynamic roughness (Pielke, 2001; Ray et al., 2006; Pielke et al., 2007). Products of human activities such as aerosols from biomass burning (which is a common agricultural practice in northern Ghana and many parts of sub-Saharan Africa), can also affect rates of cloud formation and patterns of rainfall. Ghana in the 1970s boasted of approximately 18,000 $\mathrm{km}^{2}$ of pristine rainforest, but over the years the area under forest cover has been reduced significantly. A combination of over-harvesting of timber, forest fires and encroachment has resulted in vast areas of forest and wood lands completely degraded. Annual deforestation in the savanna zones is 3 percent $(38,000 \mathrm{ha})$, exceeds the national average of 1.3 percent $(12,000 \mathrm{ha})(\mathrm{EPA}, 2000)$. It is estimated that in the past four decades, the savanna zones have lost 40 percent of their tree cover. The area most seriously affected by deforestation is the Sudan-Savanna zone with its high human and livestock population densities and intensive cultivation (EPA, 2000). The effects of such modification of the country's landscape on rainfall are reflected in many ways on water availability in the rainfall-sensitive northern regions. The absence of surface vegetation reduces the infiltration rate of surface water and reduces the replenishment of underground water reserves. Fast moving surface water increases the rates of soil erosion and degradation and reduces rates of evaporation of water back to the atmosphere. The absence of vegetation to regulate surface flows leads to the generation of floods, which have become increasingly common in northern Ghana in recent years (Armah et al. 2010; Karley, 2009). Through their influence on rainfall and the water system in farming communities, man-made activities can exacerbate existing vulnerabilities of small-holder farming households and should be addressed by long-term climate policies. 


\section{Policy Implications}

Rainfall data for Ghana has been collected for the past half century without a national climate policy. The emergent risks arising from climate variability posed to small holder farmers make it imperative to develop an integrated long-term climate policy that is adaptive to the evolving climate challenges. This policy should essentially facilitate the establishment of a comprehensive rainfall monitoring programme consisting of a dense network of aerial and ground recording devices or sensors.

The long-term climate policy framework should posses the capacity to enhance integration across sectors. High levels of integration are indicated by the capacity to consider more than a narrow sector frame of the policy framework (for example, agriculture and water could be considered together given that feedback interactions exist between rainfall variability and agricultural productivity in this agro-ecological zone). In the same vein, the climate policy could be integrated with a land use policy that specifically assigns particular parcels of land for specific purposes to facilitate proper planning of land use. The policy framework should also consider a broad range of impacts, such as social exclusion and environmental damage. In Tamale, small-holder farmers without land titles indicated that they were compelled to cultivate marginal lands, though they were aware that in doing so, the marginal lands risked further degradation.

The policy framework should allow for an opportunity to engage multiple stakeholders, address conflicts, identify inconsistencies, and integrate a variety of stakeholder perspectives (both lay and expert knowledge) within this policy framework. The small-holder farmers have developed local knowledge systems through their continuous cultivation of the land over the years. This kind of knowledge system would be quite useful in the formulation of climate policy and decision making.

Hitherto, research on agriculturally relevant variables has disproportionately focused on temporal characteristics. In this study, as in previous studies that concentrated on temporal variability, it is apparent that networks of ground rain gauges have weaknesses in accurately defining the spatial variability of rainfall events. The density of the rain gauge network often leaves large areas where rainfall is not measured and must be estimated. This uncertainty in measurement and estimation affects the quality of decision making in agricultural and climate policy framing. Thus, the long-term climate policy framework should necessarily address the spatial variability of rainfall.

\section{Conclusion}

This study assessed changes in agriculturally relevant variables using time series daily rainfall data from 1960-2007 for Tamale. Onset of rains, length and frequency of wet and dry spells, coefficient of variability of rains, recurrence periods of extreme events, as well as the general descriptive statistics of the character of rainfall are addressed. The risk of dry spells for varying numbers of days following the planting period was calculated using Markov chain modeling. Comparisons of the long-term coefficient of variation of summer rainfall to that of individual years from 1960 to 2007 were graphically represented. There has been a forward shift in the timing of planting for most food crops. This situation has left farmers with a lot of uncertainty regarding planning for this activity. The decrease in annual amount of precipitation has stabilized over the last three decades around the long-term mean. It has become more variable and seems to harbor more probabilities of extreme events. The risk of dry spells after planting have increased over the decades making farming for small-scale agriculturalists even more risky. The findings of the study suggests the need for the development of a comprehensive agricultural and climate policy that takes into account the mounting risks associated with agricultural production among small holder farmers.

\section{References}

Armah F.A., Yawson D.O., Yengoh G.T., Odoi J.O., \& Afrifa E.K.A. (2010). Impact of Floods on Livelihoods and Vulnerability of Natural Resource Dependent Communities in Northern Ghana. Water, 2:2, 120-139. [Online] Available: http://www.mdpi.com/2073-4441/2/2/120/.

Barron, Jennie, Rockström, J., Gichuki, F., \& Hatibu, N. (2003). Dry spell analysis and maize yields for two semi-arid locations in east Africa. Agricultural and Forest Meteorology, 117:1-2, 23-37.

Boko, M., Niang, I., Nyong, A., Githeko, C. A., Medany, M., Osman-Elasha, B., Tabo, R. \& Yanda, P. (2007). Africa. Climate Change 2007: Impacts, Adaptation and Vulnerability, Contribution of Working Group II t the Fourth Assessment Report of the Intergovernmental Panel on Climate Change.

Camberlin, P., \& Okoola, R.E. (2003). The onset and cessation of the "long rains" in eastern Africa and their interannual variability. Theoretical and Applied Climatology, 75:1-2, 43-54. [Online] Available: http://www.springerlink.com/content/086j9yckk95v2j8f/. 
Cheng, K.S., Hsu, H.W., Chang, K.C., \& Lee, R.H. (2004). Test and analysis of trend existence in rainfall, Proceedings of the Asia-Pacific Association of Hydrology and Water Resources. 5-8 July 2004, Singapore. Paper No. 56.

Emori, S., \& Brown, S.J. (2005). Dynamic and thermodynamic changes in mean and extreme precipitation under changed climate, Geophysical Research Letters, 32, L17706, doi:10.1029/2005GL023272. [Online] Available: http://157.82.240.168/ storage/papers/emoribrown.pdf.

Enfors, E. I., \& Gordon, L. J. (2007). Analyzing resilience in drylands agro-ecosystems: A case study of the Makanya catchment in Tanzania over the past 50 years. Land Degradation and Development, 18: 680-696. [Online] Available: http://www3.interscience.wiley.com/journal/114263244/abstract?CRETRY=1\&SRETRY=0.

Food and Agriculture Organization - FAO. (2007). Linking social protection and support to small farmer development: Ghana Case Study. Workshop on "Linking social protection and support to small farmer development in the context of food security", FAO, Rome, 17-18/01/2008.

Fowler, A. M., \& Hennessy, K.J. (1995). Potential impacts of global warming on the frequency and magnitude of heavy precipitation. Natural Hazards, 11, 283-303. [Online] Available: http://www.springerlink.com/content/w7q445p545h78g38/.

Fraser A.I., Harrod, T.R., Haygarth, P.M. (1999). The effect of rainfall intensity on soil erosion and particulate phosphorus transfer from arable soils. Water Science and Technology, 39: 12, 41-45.

Gabriel, K. R., \& Neumann, J. (1962). A Markov chain model for daily rainfall occurrence at Tel Aviv. The Quarterly Journal of the Royal Meteorological Society. 88: 375, 90-95.

Ghana Environmental Protection Agency (EPA). (2000). National action programme to combat drought and desertification. Ghana Environmental Protection Agency, Accra Ghana.

Gordon, H.B., Whetton, P.H., Pittock, A.B., Fowler, A.M., \& Haylock, M.R. (1992). Simulated changes in daily rainfall intensity due to the enhanced greenhouse effect: implications for extreme rainfall events. Climate Dynamics, 8, 83-102. [Online] Available: http://www.springerlink.com/content/hn100266h8737158/.

Graef, F., \& Haigis J. (2001). Spatial and temporal rainfall variability in the Sahel and its effects on farmers' management strategies. Journal of Arid Environments, 48:221-231.

Helsel, D.R., \& Hirsch, R.M. (1992). Statistical methods in water resources. US Geological Survey, Reston, VA.

Houghton, J.T. (2009). Global warming: The complete briefing. Fourth Edition, Cambridge University Press, New York. Chapter 5, 106-108.

Husak, G.J., Michaelsen, J., \& Funk C. (2007). Use of the gamma distribution to represent monthly rainfall in Africa for drought monitoring applications. International Journal of Climatology, 27:7, 935-944.

Karley, N.K. (2009). Flooding and physical planning in urban areas in West Africa: situational analysis of Accra, Ghana. Theoretical and Empirical Researches in Urban Management, 4:13, 25-41. [Online] Available: http://um.ase.ro/No13/2.pdf.

Kharin, V.V., \& Zwiers, F.W. (2005). Estimating extremes in transient climate change simulations. Journal of Climate, 18, 1156-1173. [Online] Available: http://www.cccma.bc.ec.gc.ca/papers/skharin/pdf/ev_cgcm2.pdf.

Kumar, V., \& Jain, S.K. (2010). Trends in seasonal and annual rainfall and rainy days in Kashmir Valley in the last century. Quaternary International, 212: 1, 64-69.

Lehmann, C.M.B., Bowersox, V.C., \& Larson, S.M. (2005). Spatial and temporal trends of precipitation chemistry in the United States, 1985-2002. Environmental Pollution, 135, 347-356.

Lobell, D., \& Field, C. (2007). Global scale climate-crop yield relationships and the impacts of recent warming. Environmental Research Letters, 2, 1-7. [Online] Available: http://iopscience.iop.org/1748-9326/2/1/014002/pdf/1748-9326_2_1_014002.pdf.

Lloyd, P. (2009). On the determination of trends in rainfall. Water $S A$, 35:3, 237-243.

MacGaffey, W. (2009). The blacksmiths of Tamale: the dynamics of space and time in a Ghanaian Industry. Africa, 79:2, 169-18. [Online] Available: http://muse.jhu.edu/login?uri=/journals/africa_the_journal_of_the_international_african_institute/v079/79.2.mac gaffey.html. 
Meehl, G.A., Arblaster, J.M., \& Tebaldi, C. (2005). Understanding future patterns of increased precipitation intensity in climate model simulations. Geophysical Research Letters, 32, L18719. [Online] Available: http://www.cgd.ucar.edu/ccr/publications/2005GL023680.pdf.

Meher-Homji, V. M. (1991). Probable impact of deforestation on hydrological processes. Climate Change, 19:1-2, 163-173. [Online] Available: http://www.springerlink.com/content/pt04273321463141/.

Mugalavai, E.M., Kipkorir, E.C., Raes, D., \& Rao, M.S. (2008). Analysis of onset, cessation and length of growing season for Western Kenya. Agricultural and Forest Meteorology, 148, 1123-1135

National Development Planning Commission NDPC. (2004). Poverty and Social Impact Assessment Study. Tracking Vulnerability and Exclusion in Ghana. Prepared by Sync Consult, Accra

Nicholson, S. (2005). On the question of the "recovery" of the rains in the West African Sahel. Journal of Arid Environments. Special Issue on The "Greening" of the Sahel 63:3, 615-641

Oladipo, E.O., \& Kyari, J.D. (1993). Fluctuations in the onset, termination and length of the growing season in Northern Nigeria. Theory Appl. Climatol, 47:4, 241-250. [Online] Available: http://www.springerlink.com/content/n287375u40864713/.

Olsson, L. (2008). Greening of the Sahel. Commissioned article for Encyclopedia of the Earth Boston University. [Online] Available: www.eoearth.org.

Pielke, R.A., Adegoke, J., An-Przekurat, A.B., Hiemstra, C.A., Lin, J., Nair, U.S., Niyogi, D., \& Nobis, T.E. (2007). An overview of regional land-use and land-cover impacts on rainfall. Tellus, B 59:3, 587-601.

Pielke, R. (2001). Influence of the spatial distribution of vegetation and soils on the prediction of cumulus convective rainfall. Reviews of Geophysics, 39, 151-177.

Ray, D., Nair, U., Lawton, R., Welch, R., \& Pielke, R. (2006). Impact of land use on Costa Rican tropical montane cloud forests: Sensitivity of orographic cloud formation to deforestation in the plains. Journal of Geophysical Research, 111, D02108. [Online] Available: http://web.ics.purdue.edu/ dkray/pdf/2005JD006096\%5B1\%5D.pdf.

Sachs, J.D. (2008). Common Wealth: Economics for a Crowded Planet. Penguin Press.

Sansom, J. (1998). A hidden Markov model for rainfall using breakpoint data. Journal of Climate, 11:1, 42-53. http://journals.ametsoc.org/doi/full/10.1175/1520-442\%281998\%29011\%3C0042\%3AAHMMFR\%3E2.0.CO\% 3B2.

Seaquist, J. W., Hickler, T., Eklundh, L., Ardö, J., \& Heumann, B.W. (2008). Disentangling the effects of climate and people on Sahel vegetation dynamics. Biogeosciences Discuss, 5, 3045-3067.

Seidu, A. (2009). Urban Agriculture: Factors Affecting the Decision to Grow Vegetables in Tamale Metropolis. The Icfai University Journal of Agricultural Economics 6:2, 51-63. [Online] Available: http://ideas.repec.org/a/icf/icfjag/v06y2009i2p51-63.html.

Sivakumar, M.V.K. (1992). Climate change and implications for agriculture in Niger. Climatic Change, 20, 297-312. [Online] Available: http://www.springerlink.com/content/g573202234j624hq/.

Sharma, T.C. (1996). Simulation of the Kenyan longest dry and wet spells and the largest rain-sums using a Markov model. Journal of Hydrology, 178, 55-67.

Stern, R., \& Knock, J. (1998). INSTAT climatic guide. Statistical Service Centre, University of Reading. UK, 285 pp. [Online] Available: http://www.reading.ac.uk/SSC/media/ICRAF_2007-11-15/InStat/docs/climatic.pdf.

Stern, R. D., \& Coe, R. (1984). A model fitting analysis of daily rainfall data. Journal of the Royal Statistical Society. Series A 147:1, 1-34. [Online] Available: http://www.jstor.org/pss/2981736.

Stumpf, E. (1998). Post-harvest loss due to pests in dried cassava chips and comparative methods for its assessment. - A case study on small-scale farm households in Ghana. PhD Thesis, Faculty of Agriculture and Horticulture, Humboldt-University Berlin.

Sultan, B., Baron, C., Dingkuhn, M., Sarr, B., \& Janicot, S. (2005). Agricultural impacts of large-scale variability of the West African monsoon. Agricultural and Forest Meteorology, 128 1-2, 93-110.

Tesfaye, K., Walker, s. (2004). Matching of crop and environment for optimal water use: the case of Ethiopia. Physics and Chemistry of the Earth, 29, 1061-1067.

Webb, T.J. (2005). Forest cover-rainfall relationships in a biodiversity hotspot: the Atlantic forest of Brazil. Ecological Applications, 15:6. 


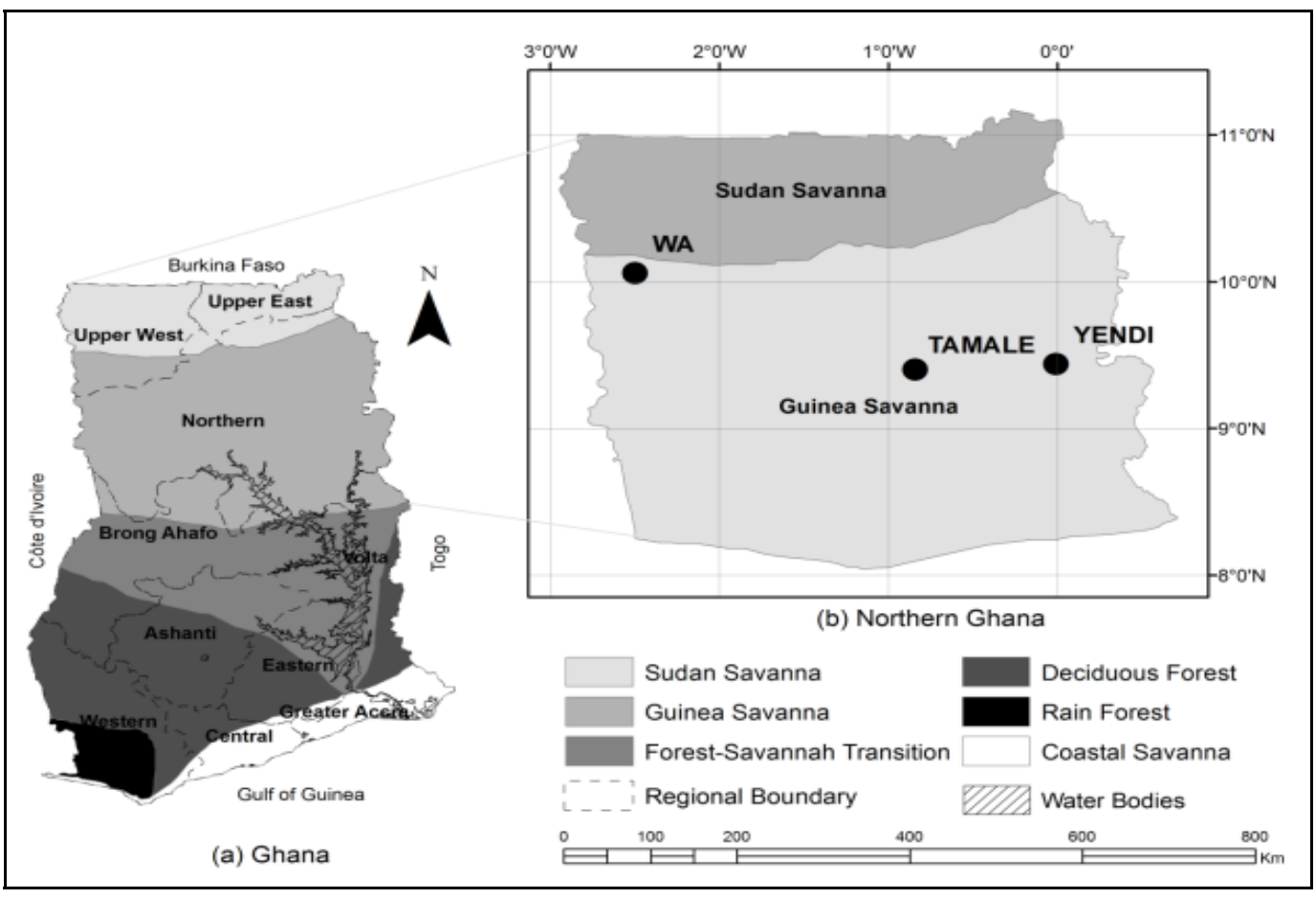

Figure 1. Map of Ghana showing the guinea savanna agro-ecological zone and Tamale from where the analyzed data is collected

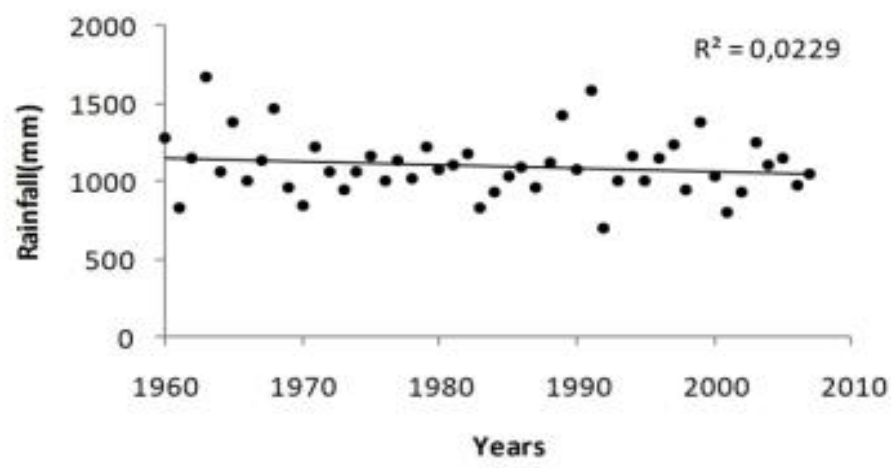

Figure 2. Annual rainfall of Tamale 1960-2007

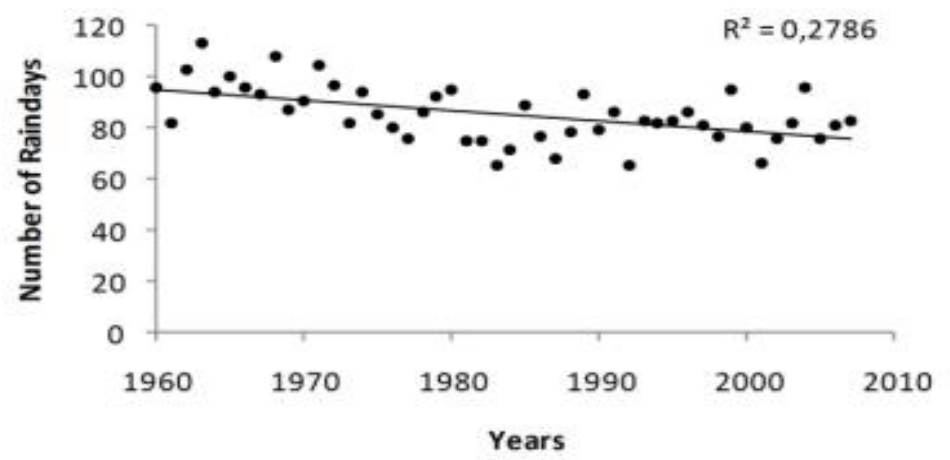

Figure 3. Number of rain days 1960-2007 


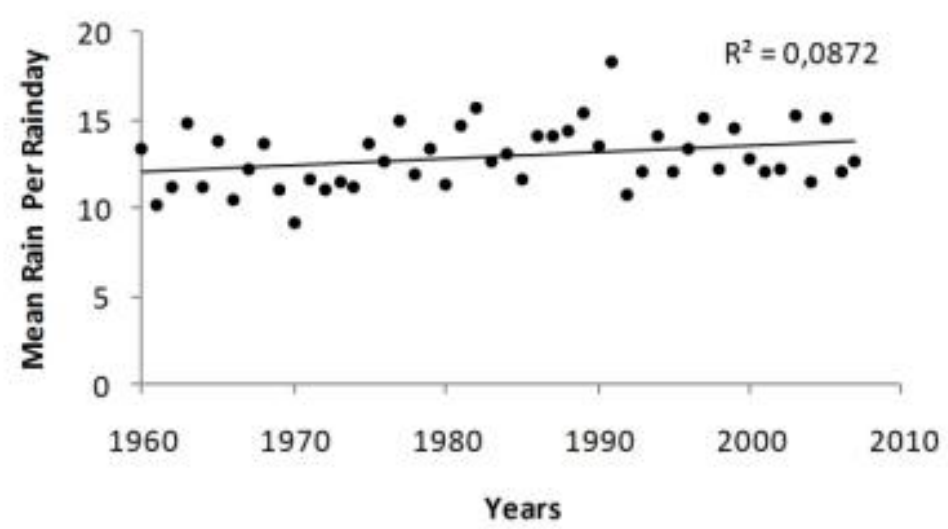

Figure 4. Mean rainfall per rain day 1960-2007

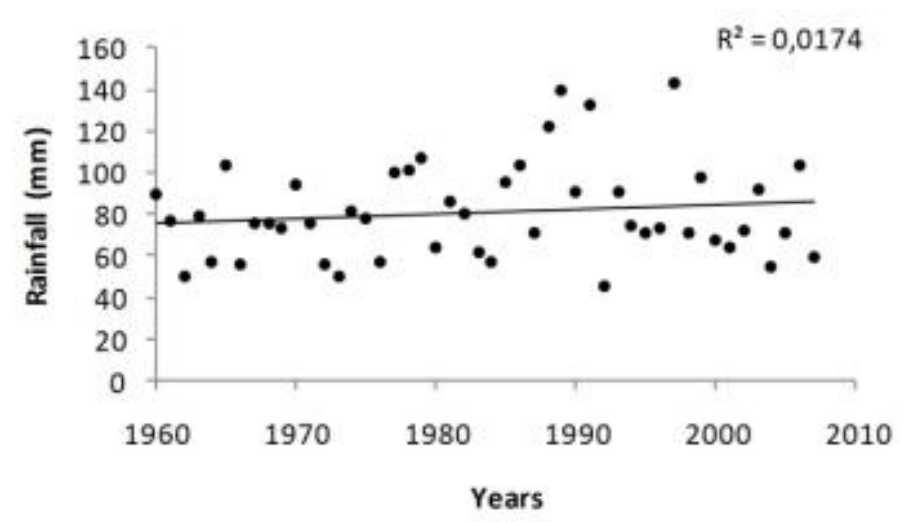

Figure 5. Maximum daily rainfall for each year 1960-2007

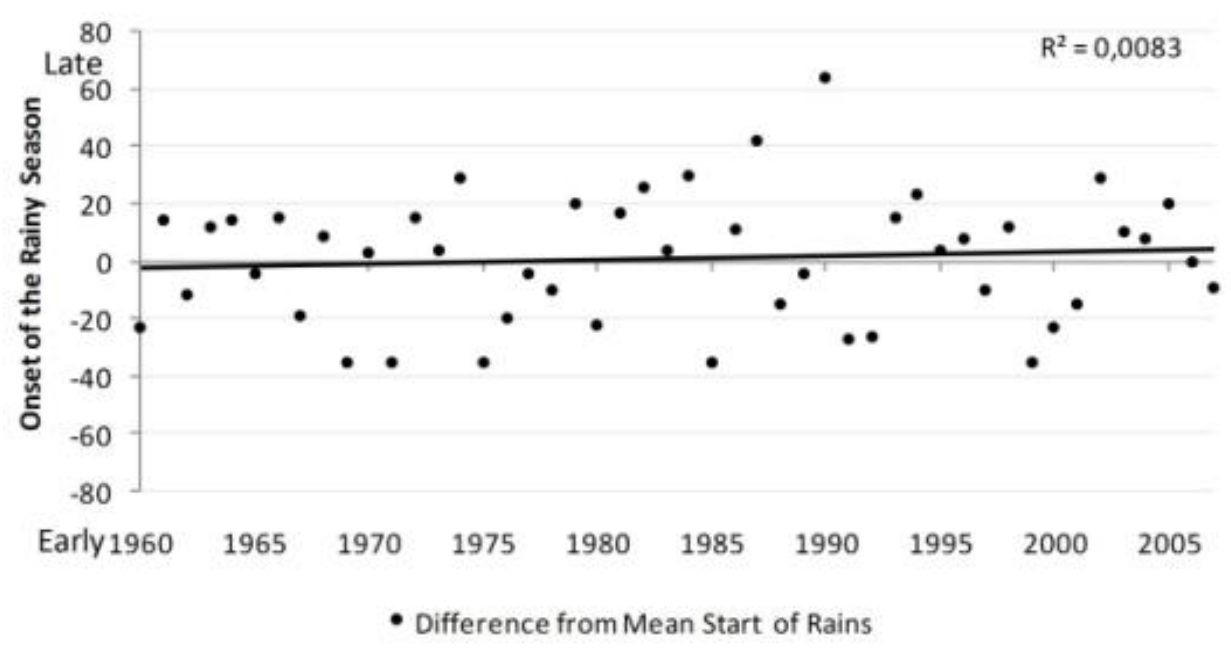

Figure 6. The onset of the rainy season from 1960-2007. The mean onset of rains (represented in the figure as 0) is the 6th of May. Negative values represent the number of days the rainy season started before the mean start date - early start, while positive values represent a start later than the mean start date 


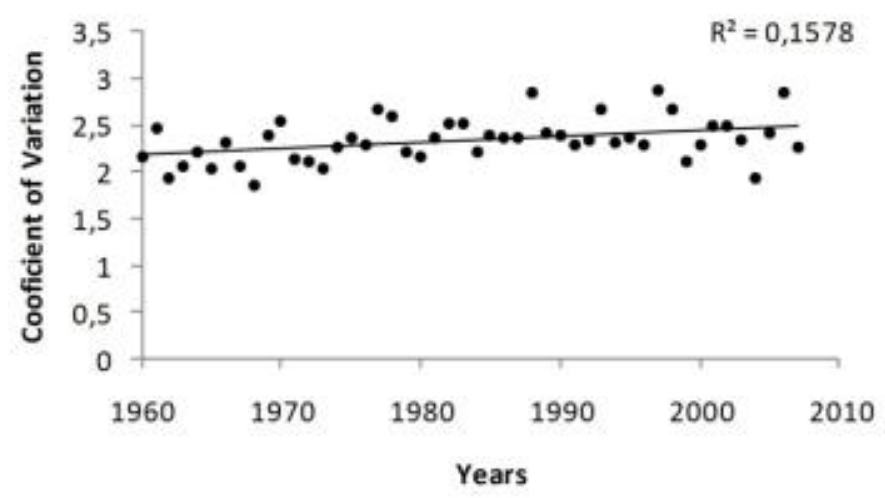

Figure 7. Coefficient of variation of summer rainfall 1960-2007

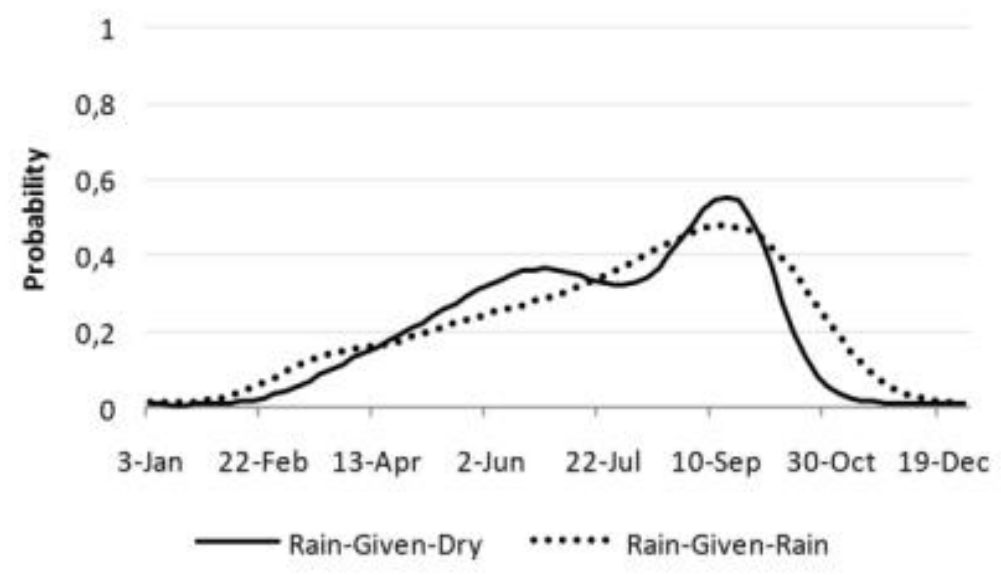

Figure 8. Probabilities of rain based on all days and for all years (1960-2007) from a first-order Markov model

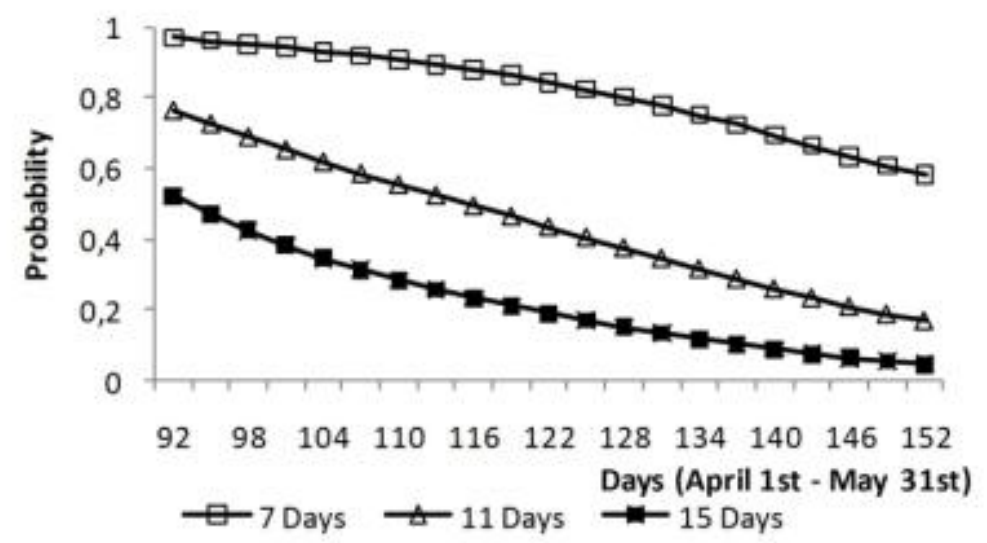

Figure 9. Probability for dry spells of lengths 7, 11 and 15 days from the 1st April (day 91) - 31st May (day 152) 